\title{
RAMON XIRAU
}

\section{Bernardo de Balbuena, alabanza de la poesía}

\footnotetext{
B
} ALBUENA vive plenamente en el período barroco, pero Balbuena, exactamente contemporáneo de Góngora, cuya obra conocía, no es siempre barroco. Hay en él mucho de clásico - lo veía con su perspicacia acostumbrada Mënendez Pelayo. En realidad, el poeta, gran conocedor de los clásicos, estaba todavía muy ligado al clasicismo renacentista. Su poesía no suele ser sintácticamente compleja. Sus fuentes, en cuanto a la épica, son, principalmente, Ariosto y Boyardo, en cuanto a la novela pastoril, lo ha probado Rojas Garcidueñas, Sannazaro y por lo que toca a la lírica, Virgilio y Teócrito. Ei: pocas palabras, Balbuena es un barroco clásic o, si se quiere, un clásico que sabe de las nuevas formas poéticas y las utiliza cuando le son necesarias. Pero pasemos a algunos aspectos de la vida del poeta detalladamente analizada, aunque demasiado psicoanalíticamente, por Rojas Garcidueñas.

Manchego, Bernardo de Balbuena, hijo ilegítimo, nace en Valdepeñas en 1562. Su padre, que tenía propiedades en Nueva España, regresa a tierras mexicanas en 1564. Balbuena de niño no lo había conocido. Se queda Balbuena en España con su madre y en 1584 pide "licencia" para viajar a México donde vive con su padre durante algún tiempo. Llega al país a los veintidós años, unos sesenta y tres después de la Conquista; es decir, se encuentra con un país ya desarrollado, con una capital llena de palacios y muchas ciudades ya fundadas, de Veracruz a Puebla, de Chihuahua, en el Norte, a Oaxaca en el Sur. En 1585 gana un concurso poético, se instala en Guadalajara, vuelve a ganar otro concurso o certamen en 1590 y en 1592 es nombrado capellán de la Audiencia de Guadalajara donde empieza el Bernardo que terminará diez años después (recuérdese que esta epopeya consta de 40,000 octavas reales). Balbuena vive largo tiempo en el reino 
de Nueva Galicia (los actuales estados de Jalisco y Nayarit), y reside en un pequeño pueblo sufícientemente aislado cercano a Compostela. Algunos se han preguntado cómo podía escribir Balbuena en zona tan alejada y aislada. No veo aquí ningún problema. Ya de España traía Balbuena un buen bagaje cultural, estaba al corriente de la literatura de su tiempo y, como vimos, de tiempos clásicos. En 1593 escribe Balbuena la Cirandeza mexicana, amplio poema del cual me ocuparé especialmente. El libro a parece en 1604. La Grandeza está dedicada a Doña Isabel de Tobar y Guzmán, de quien el poeta estaba enamorado. Pero Balbuena tiene ambiciones de otro tipo. En 1606 viaja a Madrid - va no regresará a México donde, a pesar de haber vivido únicamente unos veintidós años, se enamora del país y se convierte, lo vió Menéndez Pelayo, en poeta mexicano.

Balbuena vive brevemente en Madrid. En 1607 se doctora en teología en la universidad de Sigüenza, el mismo año en que Quevedo publica los Sueños. En 1608 hace publicar su ya novela pastoril Siglo de Oro en las Selvas de Erifile que había escrito en su primera juventud. El libro, el primero de Balbuena, al cual no me referiré más adelante, es una novela pastoril que el poeta explicó en prosa. El estilo alegórico del Siglo de Oro será típico del Bernardo, aunque no de la Grandeza Mexicana. En 1608 logra Balbuena que lo nombren abad de Jamaica, donde llega en 1610. Su intento por convertir Jamaica en obispado fracasa. En 1623 alcanza altas jerarquías; es nornbrado obispo de Puerto Rico donde llega en 1626, después de haber sido dos años provincial de Santo Domingo. El Bernardo, escrito como vimos entre 1592 y 1602 , aparece en Madrid en 1624. Muere Balbuena en San Juan en 1627. Ha visto toda su obra publicada, esta obra que consta básicamente de tres obras: Siglo de Oro. Girandeza, Bernardo. A ntes de analizar estos dos últimos libros, es necesario decir algo sobre la poética y la retórica de Balbuena, quien claramente expuso sus ideas en la introducción al Bernardo y sobre todo en el Compendio en alabanza de la poesía, pequeño tratado verdaderamente original.

En el Bernardo, poema abigarrado y a veces arrebatador, cuenta Balbuena cómo su "fábula" se refiere al pasado y al futuro. El héroe de la obra es, naturalmente, Bernardo del Carpio. Ciertamente, lo han visto varios críticos, Balbuena no presenta a sus personajes de bulto, no sabe otorgarles un carácter preciso. Pero hay que darse cuenta de que el verdadero personaje del Bernardo, es el mundo hispánico, Iberia en su 
totalidad. El Bernardo debe mucho a Ariosto y a Boyardo; debe mucho también a Tasso y constituye un abigarradísimo gran poema que no alcanza la altura de la Araucana y, mucho menos de este gran poema, grande entre todos los de su género, que es Os Lusiadas de Camoens. Pero pasemos a las ideas estéticas de Balbuena.

El Bernardo remite al destino de España. Para escribirlo Balbuena recurre a ciertos artificios, entre los cuales el principal consiste en empezar no por el principio, sino "enmedio", porque "...hay dos modos de contar y hacer relación de esas mismas cosas, uno natural, que es el histórico, y otro artificial, que es el poético, y así como sería defecto en el discurso natural no comenzar las cosas con claridad desde sus principios... así lo sería en el artificial contarlas sin artificio". En pocas palabras, hay que separar historia y poesía y, en ésta, proceder con arte, imaginación, invención. Lo cual constituye la especificidad y la novedad creadora que es la obra poética. Balbuena es partidario de lo que hoy llamaríamos "suspenso", cosa que practica a lo largo del Bernardo. Por fin, hay que ver el Bernardo como una obra alegórica. Al final de cada uno de sus veinticuatro libros, Balbuena nos refiere la "moralidad" del poema.

Estas ideas, muchas veces llevadas a cabo con gran eficacia y casi siempre con claridad y vigor, remiten ante todo a la poesía épica. ¿Qué sucede con la poesía en general'?

En el Compendio apologético en alabanza de la poesía. Balbuena es muy preciso y en verdad original, por más que el poeta sea eco de muchos antecedentes - ilo son siempre en verdad? - del mundo grecolatino y de origen bíblico.

La poesía es "digna de grande cuenta" porque gracias a la imaginación, esta imaginación tan condenada por los franceses del siglo XVII y tan importante en las letras de España o Inglaterra, permite que nos alejemos de nuestros "achaques". Es probable que Balbuena recuerde, como él lo dice, a Patricio pero Balbuena es totalmente Balbuena cuando escribe que los poetas "deben ser honrados de las ciudades y puestos en lugares eminentes y dignidades nobles por ser partos dichosos y raros de la naturaleza, pues ninguna cosa lo es tanto en los siglos y edades del mundo como un perfecto poeta y un consumado orador...". No, ni Pascal tenía razón al decir que la imaginación es "la loca de la casa" ni Malebranche cuando escribía que la imaginación es "la loca que juega a estar loca".

La invención es "divina", es una "divina invención". Don- 
de yerra Balbuena es en pensar que Platón coloca al poeta por encima de todos los mortales. No importa. Balbuena, al citar a Platón y a tantos otros más, está refiriéndonos, muchas veces con citas justas, a su propia idea de la poesía, y de sü compañera, la música.

Pero, ¿por qué insistir tanto sobre la imaginación? La cosa es clara; se trata de una forma, acaso la más alta, de conocimiento. La poesía sirve para ponerle "nombres a las cosas" -idea por cierto extremadamente moderna ${ }^{1}-$, lo cual nos conduce a "conocerlas". Así la poesía depende de una profunda virtud. Remitiendo a Orígenes, el patrístico de Oriente, nos dice Balbuena que "una cierta virtud espiritual... inspira al poeta y le llena el pensamiento de una divina fuerza y vigor" y, en una tradición muy de su tiempo, al citar a los clásicos griegos Orfeo, Arión, Safo, afirma Balbuena que "aprendieron los griegos y latinos de los hebreos": La idea no es nueva. Varios padres de la iglesia pensaban que Platón había leído la Biblia, entre ellos Eusebio, a quien Balbuena cita.

Pero, ¿cual es el origen de esta "virtud espiritual" que define al poeta? No hay duda, el poeta es un "inspirado".

Es que el poeta tiene "ciertos recuerdos que el alma interiormente siente de aquella consonancia y armonía que lo hacen estar en "consonancia y armonía" con el mundo. Música y poesía, acaso pitagóricamente, remiten al universo, la poesía, "alma de la música".

¿Cómo se expresa el poema?; ¿cómo puede y debe expresarse? Escribe Balbuena: "La elegancia de las palabras, la propiedad de la lengua, las suaves y hermosas traslaciones, los modos agudos, galanos y nuevos, es decir, la copia, la abundancia, claridad, altivez, el delicado estilo; lo ordinario y común dicho por modo particular y extraordinario, y lo que más es, las cosas extraordinarias, nuevas y difíciles por modo ordinario y fácil, todo es de la jurisdicción del poeta, que tiene obligación a ser general y cursado en todo, en prosa y en verso, en uno y otro género, y que en todo haga y diga con ciencia y caudal". Es posible que en esta idea de la poesía y del poeta se encuentren resabios del "uomo universale" renacentista; es seguro que Balbuena define su propia forma de escribir sin olvidar - la palabra se repite- la "novedad" en el decir.

1 Pienso, por ejemplo, en la importancia que da Heidegger a los poetas en cuanto al conocimiento. Si así lo quiere el lector puede leer mi Poesía y conocimiento, 1979 . 
La poesía es la forma imaginativa del conocimiento, pero " además "corre parejas" con los "primeros años" del mundo. En este punto Balbuena es original y lo es en una tradición acaso pitagórica. Poesía y mundo se unen, porque el mundo, hecho por el Creador de una "bellísima contraposición", tiene en el poema, "palabras en contraposición", su copia fiel. Más claramente, el universo mismo es poético. Balbuena escribe: "...a nuestro propósito basta que toda la compostura del mundo sea una poesía y verso espiritual". Por lo demás, Dios gusta de los versos y los cantos: "los espíritus celestiales eternamente y sin cesar le cantan himnos de glorias y alabanzas que corresponde y remeda el ordinario canto de la Iglesia católica." También sabemos, por el Apocalipsis que los primeros cristianos cantaban "alabanzas y aleluyas". Lo cual no debe entenderse "metafóricamente"; se trata de "voz y música verdadera y sonora".

Hasta aquí sabemos, entre otras cosas, que la poesía conoce al dar nombre a las cosas y que el poema responde al gran poema del mundo que cantan ángeles, hombres y, seguramente, Adán, el primer hombre. En dos ocasiones Balbuena cita a Hermes Trismejisto como si fuera un pensador cristiano. La cosa no es nueva; en la Florencia de Ficino y Pico della Mirandola, Hermes se incorporaba a una tradición cristiana que no dejaba de tener aspectos herméticos. No me interesa saber si Balbuena profesaba o no alguna parte de hermetismo. Lo más probable es que no lo profesara. Lo que me interesa es ver que, aun cuando barroco, Balbuena estuvo siempre muy hondamente ligado a la tradición italiana renacentista:

¿Qué más decir sobre la poesía? Por lo pronto que "a todos hace compañía", "a todos regala y consuela, a todos agrada y levanta el espíritu". Nada más lejos que una concepción decorativa del poema. El poema es oora del espíritu y eleva al hombre a su dignidad primera. Por esto es gran poeta David y por esto lo es Salomón "el más sabio de los hombres".

¿Cuáles son los poetas preferidos de Balbuena? Los nombres son muchos y muchos de ellos están olvidados. Recuerdo tan solo a los más conocidos y a aquellos que han dado valor a la poesía castellana. Entre los clásicos, Balbuena cita especialmente a Píndaro, Virgilio, Horacio, Tibulo Menandro, Eurípides,

2 El poema es hermoso. Es laboriosa su lectura. Valdria la pena, trabajo no fácil, que se intentará algún día abreviarlo sin perder su secuencia No es éste el lugar de hacerlo. 
Virgilio "el Platón de los poetas", Plauto. Estos poetas, además, fueron a migos de césares y príncipes, quienes sienten apoyo en la poesía. En el caso de España, entre muchos otros, Balbuena hace memoria de Lucano, Séneca, Marcial, Silio Itálico, el Márques de Santillana, Boscán, Garcilaso, "el agudísimo don Luis de Góngora", "el gran don Alonso de Ercilla". La lista de Balbuena es intencionada. Pretende no solamente recordar una larga tradición poética sino mostrar que "de filósofos, de teólogos, de santos, de Pontífices, monarcas y reyes, y de ambos derechos, civil y canónico, vemos estimada, amparada y defendida la poesía y aprobada por ciencia noble". Sin duda la poesía es un "entretenimiento agradable y noble", pues "al fin es un sabroso vino de la imaginación, que moderado alegra el espíritu, regala el entendimiento, deleita la fantasía, menoscaba la tristeza y da perpetuo y maravilloso gusto a sus profesores que, como dice el refrán, quien canta sus mảles espanta".

Como defensa de la poesía, este Compendio de Balbuena es superior, aunque menos conocido, que la famosa Defense of Poesie de Sir Philip Sidney. Por otra parte, la poética de Balbuena no es solamente una poética, es, como se habrá visto, toda una visión del mundo y un canto a la naturaleza y a la divinidad.

El Bernardo tanto por su longitud como por su complejidad es irresumible. Me limitaré a recordar algunos de sus principales momentos. ${ }^{3}$ poema. ${ }^{4}$

Sigamos, muy abreviadamente, los diez primeros libros del

Después de la introducción en que se señala la intención de la epopeya como ya hemos visto, Balbuena empieza por describir Francia y España, nos presenta a la hada Alcina y el palacio del gigante Morgante. (I) Alcina habla con Morgana y le explica el origen godo de Bernardo del Carpio mientras promete darle las armas de Aquiles. Ferraguto libra a una ninfa de un sátiro. La ninfa le muestra algunos de los grandes capitanes de España(II). Ferraguto, lleno de envidia hacia Bernardo, va en busca de éste para "probarse con él". El libro termina con una hermosa descripción de una fiesta francesa (III). Por su parte, Orontes, por artilugios de magia, deja a Malfesí colgado de un árbol, se

3 El poema es hermoso. Es laboriosa su lectura. Valdría la pena, trabajo no fácil, que se intentar algún día abreviarlo sin perder su secuencia No es éste el lugar de hacerlo.

4 Los números romanos remiten al númcro del Libro que se resumen. 
mencionan los mártires españoles, se promete a España un nuevo mundo - tema muy central en el Bernardo-. Por milagro, Bernardo se encuentra en un galeón con Angélica la hermosa y es armado caballero "por mano de un rey persiano". Siguen toda una serie de conversaciones y diálogos y aparece Yusuf (V). Orlando y Garilo discuten cuál ha de ser "el don mayor de la fortuna". Bernardo se dirige a una isla toda frescura donde pretende curar a Orimandro. Se relatan la vida del habitante de la isla, Guandémaro, las aventuras de Ferraguto en tierra de moros y no faltan - ¿podían faltar en esta clase de poema? - los encantamientos (VI y VII). El poeta remite a luchas contra los moros, los cristianos logran arrebatar a Florinda. Angildos cree que Florinda está muerta y, enamorado de ella, quiere matarse. Bernardo encuentra a Angélica en las garras de un dragón. Florinda no ha muerto. Proteo le cuenta quiénes son sus padres y vuelve en sí:

Despertó sin sentido alborotada, de sudor y de lágrimas cubierta, y en ver su tierno amado más turbada, sospecha todavía que está muerta,

Un capitán trae a la "mora" Florinda y a un moro presos (VIII y IX).

El libro X termina con esta moral: "De los sucesos de Florinda se muestra el cuidado que Dios tiene de los inocentes y cómo ninguna desgracia llega a quien él de su mano quiere guardar".

A partir del Libro XI sabemos que unos corsarios han raptado a Angélica. Bernardo la sigue mientras cuenta a Orimandro cuál es su origen. Por su parte, Garilo roba a Orlando y a sus compañeros que se convierten en estatuas de oro en una sala encantada mientras él escapa:

No hubo francés que no alargara el paso por si hallara detrás de las pinturas, los tesoros de Midas o de Crado (XII)

Después de mostrar que la "avaricia es un vicio torpe" (XII), Bernardo del Carpio, entre muchas otras cosas, libera a Angélica la hermosa (XIII) y conoce por vez primera los orígenes de esta joven mujer -en este canto, una eficaz y excelente 
descripción de Asia-(XIV). Malgesí buen mago, hace que su navio vuele y, acompañado por Reynaldo, Morgante y Orimandro, sobrevuela Europa (XV). El viaje prosigue - estos viajes aéreos son de lo mejor de la obra-, muestra la belleza de Francia e Italia y la "grandeza" de España (XVI). Bernardo, por su parte, ahora desde un collado del Parnaso ve no sin horror y sorpresa la variedad de monstruos que surgen de la tierra por la puerta de Engaño (XVII). El libro XIII contiene una de las partes mejores del poema; el vuelo de Malgesí sobre América, de la Patagonia al Norte de la Nueva España.

Desde "los bajos antípodas del mundo" "hasta los encubiertos Patagones", Balbuena no olvida los lugares "por donde Magallanes, sin contienda del rico Oriente halló la inútil senda". Prosigue el hermoso vuelo por los Andes, Brasil, "los temidos desiertos del Dayrén", Potosí, Panamá y el vuelo llega a la Nueva España donde se vislumbran "de Chiapas los desiertos arenales" y de "Guadalajara la florida foja", los ricos "mixtecas", las "nevadas alturas de Perote, Panico (¿Pánuco?), Guarulco, Mechoacán (Michoacán), Colima, Acapulco, Tlajomulco, "la abundante laguna de Chapala que al Océano en profunda anchura iguala", Zacatecas, Culiacán, el "gran volcán de Jala" en erupción. Pero, ¿qué ha querido cantar Balbuena? El mismo lo dice en la "moral" que corresponde al libro: "El gran vuelo del sabio Malgesí ya hemos dicho que es figura de vida contemplativa, que de las cosas divinas inferiores para la mira de las celestiales, con la cual llega a la felicidad del nuevo mundo, que es la bienaventuranza prometida al hombre, como a la Monarquía española las Indias Occidentales". Aquí lo importante es la conciencia de la novedad de otro mundo, el Nuevo Mundo (XVIII).

Seguimos en América y proseguimos en México. Tlaxcán, personaje difícilmente identificable, cuenta las hazañas de Cortés, remite a los reyes católicos y a Colón. Concluye Balbuena: "En las grandes hazañas de Cortés se muestra la magnanimidad y atrevimiento de un verdadero capitán español" (XIX). Bernardo, ahora rodeado de fantasías y encantamientos en el castillo del Carpio (XX), vence los encantamientos y, en un espejo, vé su linaje. El origen mitológico de su nombre es helénico y africano (XXI). Carlomagno tiene sueños premonitorios (XXII), regresamos a la magia y a una excelente narración acerca del campo francés (XXIII) y, fin del poema (XIV), llegamos a la batalla de Roncesvalle. 
Cayó muerto Roldán, quedando vivo su eterno nombre; su alma arrebatada feroz voló a su esfera, y su gallardo cuerpo a los pies cayó del Gran Bernardó

El poema termina con una alegoría sorprendente y a la vez importante, puesto que narrá la intención toda del poema:

“...y en las muertes de Reinaldo y los demás paladines, y últimamente en la de Orlando, que era encantado, muerto por Bernardo con la espalda Batisarda, muestra cómo no hay encantamiento, armas ni defensa que basten contra la muerte"

El extensísimo Bernardo mezcla la historia hecha mito con lo idílico, la alegorías, temas de las novelas pastoriles (que ya Balbuena había empleado en el Siglo de Oro), descripciones extraordinarias - tanto por extrañas como por magnificientesargumentos religiosos en las diversas alegorías, lecciones morales, magia, fe, sensualidad, espléndidas metáforas y ritmos épicos. Es cierto, el poema se dispersa y pierde unidad, pero no pierde nunca de vista la grandeza de España, la conquista de lo nuevo del Nuevo Mundo, la batalla de Roncesvalles. Sin duda. las mejores partes del poema suelen encontrarse en las descripciones de los tres viajes mencionados más arriba, en los momentos donde predomina la magia y algunos momentos heroicos, principalmente acaso, la totalidad del libro XXIV y último.

El Bernardo no alcanza la altura de los mejores poemas épicos del Renacimiento italiano ni aun del español o ibérico (ante todo, lo repito, Camoens). Queda, con todo, como la obra a veces excelente, de un poeta excepcional.

La Grandeza es la mejor obra de Balbuena. Tiene sus antecedentes, en cuanto a descripciones de la ciudad de México: las de Cortés y Bernal Díaz ante la ciudad de Tenochtitlan, los diálogos latinos de Cervantes de Salazar, muchas páginas de Juan de la Cueva. El poema fue visto con claridad por Menéndez Pelayo aun cuando Alfoso Reyes, con razón, critique un aspecto de la interpretación del crítico español. No se trata aquí de un mundo tropical; se trata, como lo dice Reyes, de un poema de la "polis".

Dedicado, lo hemos visto, a Doña Isabel de Tobar y Guzmán, la Grandeza se inicia con un "argumento" donde se anuncian con precisión los ocho capítulos que lo componen más el epílogo. Vaya el argumento: 
De la famosa México el asiento origen y grandeza de edificios, caballos, valles, trato, cumplimiento, letras, virtudes, variedad de oficios, regalos, ocasiones de contento, primavera inmortal y sus indicios gobierno ilustre, religión, estado todo en este discurso está cifrado.

La Grandeza mexicana idealiza, sin duda, la ciudad de México y, en conjunto, a la Nueva España. Pero las exageraciones de Balbuena son válidas porque son poéticas y, ya lo sabemos, para él la poesía es cosa de imaginar y conocer transformando la realidad, en un universo espiritual. Veamos algunos de los mejores momentos de la Grandeza, capítulo a capítulo sin exceso de comentarios. En el capítulo I, sin duda Balbuena exagera cuando habla de México como la ciudad que es "centro de perfección, del mundo quicio". Pero se vuelve totalmente realista y a la vez finamente poético cuando, en un terceto, describe el lugar, el "asiento" de la ciudad:

Sobre una delicada costra blanda, que en dos claras lagunas se sustenta cercada de olas por cualquiera banda

Y así era México: subsuelo blando y dos lagunas, una de agua dulce, la otra de agua salada.

En el capítulo II - Origen y grandeza de edificios- se refiere Balbuena brevemente al "bravo brío español", acierta en la realidad y en el deseo cuando afirma que los españoles han añadido "al mundo una española isla y dos Españas", remite muy brevemente al mundo indígena cuando recuerda que existió aquí "oscuro origen de naciones fieras" y señala el emblema de los mexicas. ("del principio del águila y la tuna"), pero no quiere hacer historia. Ya lo hemos visto, la historia queda para los historiadores, no para los poetas. Por esto afirma Balbuena: "Sólo diré de lo que soy testigo". Las calles de México son, en efecto, una suerte de ajedrez: "a las del ajedrez bien comparadas". El elogio de casas y palacios era realista. Basta, hoy en día, recorrer el antiguo centro de la ciudad de México - no terminado en vida de Balbuena - para poder decir que fue la ciudad de los palacios. 
El capítulo III - “caballos, calles, trato, cumplimiento”hace gala de erudición barroca:

en México al primer lugar subiera aunque para alcanzarlo le ayudaran las espuelas del tiempo y su carrera

Pero, ¿hasta qué punto es barroco Balbuena? Lo es moderadamente porque es un espíritu clásico.

Letras, virtudes, variedad de oficios es el título del capítulo IV. No olvida Balbuena, al cantar la grandeza de México, a "la gente mendiga, triste, arrinconada" que opone a la belleza natural, tan hermosamente descrita. Termina el capítulo con la habitual cuarteta:

Milagros y portentos de natura nacer de las retamas clavellinas porque vivir en pueblos miserables son galeras de Dios en este mundo.

El idilismo, que no deja de ser descriptivo, obedece en Balbuena tanto al encontrarse con un Nuevo Mundo, como a los recuerdos heroicos aún recientes de la conquista, que, por cierto... no fue tan ídilica. El capítulo $\mathrm{V}$-regalos, ocasiones de contento, es a la vez lírico y realista. Así en estos dos tercetos:

La fresca yedra, que en el tronco y falda del olmo antiguo en mil engarces sube sus bellos enrejados de esmeralda. Aquí do el mundo en maridaje altivo a la yedra y a laurel teje y enrama la casta palma y el amable olivo

No deja Balbuena de ser irónico: "de mujeres tocados y quimeras / de maridos carcomas y dolores"). Predomina, sin embargo, la serenidad precisa y viva así como la idea, presente en el Bernardo, de España y la Nueva España como centro del mundo. Precisión cuando se refiere a las damas:

Cuantas rosas de abril, el cielo estrellas, Chipre azucenas, el verano flores aquí se crían y gozan damas bellas. 
En cuanto a la ciudad, "cielo del mundo" - lo es por su altitud-se convierte en eje del mundo hispánico.

El Capítulo VI (Primavera inmortal y sus indicios) es acaso, en su barroquismo mitigado, la mejor parte del poema - un poema, por cierto, que mantiene siempre un alto nivel poético-

Vayan algunas citas como ejemplo de este mundo real-ideal:

alli enredado

cl ruiseñor en un copado aliso

el aire deja cn suavidad bañado

el pino verde reventando perlas

de transparente goma

el mastuerzo morda\% de enredos lleno

Y, de manera más mitológica:

alegres flores, que otros tiempos fueron

reyes del mundo, ninfas y pastores,

$y$ en flor quedaron porque en flor se fueron.

Gobierno ilustre, capítulo VII. La ciudad de México es el centro del Nuevo Mundo ("del nuevo mundo la primera silla"). Balbuena cita a los virreyes, no sin desorden cronológico (Azevedo, Zúñiga, Mendoza, Velasco), a los arzobispos, sin dejar de recordar a las personas más modestas: los trabajadores y empleados. En el capítulo VIII - Religión y Estado-, vuelve Balbuena a describir las flores (rosas, claveles, azucenas, "de color suave y vista regalada") y enumera las muchas iglesias y conventos que ya existían en los años en que Balbuena escribía. En cuanto al "epilogo", capt́tulo final, después de habernos dicho, lo cual es verdad, que el pueblo ha empleado un "precioso buril", tiende a reunir lo que se ha descrito antes y concluye:

de mi pobre caudal el corto empleo

recibe en este amago, do presente

conorcas tu grandeza, o mi deseo

de celebrarla al mundo eternamente.

Balbuena, espléndido poeta, debe ser recordado y sobre 
todo releído, Balbuena, el que pensaba que "toda la compostura del mundo" es "una poesía y un verso espiritual".

\section{BIBLIOGRAFIA}

FRANK DAUSTER, Breve historia de la poesia mexicana. 1956.

LUIS ADOLFO DOMINGUEZ, prólogo a la Cirandeza Mexicuna y' compentio ch alahanza de la poesia. 1980.

IOSEPH FUCILLA, "Bernardo de Balbuena"s", Siglo de Oro and its sources", Hispanic Rovich, XV,I.

PEDDRO HENRIQUEZ UREÑ A: Las corriontes literarias de la América hispánica, 1949. ALFONSO MENDEZ PLANCARTE, Poetas novohispanos. Primer Siglo(1521-1621), $1942^{2}$

MARCELINO MENENDEZ Y PELAYO, Historia de la poesia hispanoamericana, 1911.

FRANCISCO MONTERDE. Prólogo a (irandeza meviana l' fragmentos del Siglo de Oro l' El Bernardo, 1954.

JOSEFINA MURIEL, C'onventos de monjas en la Nueva España, 1940.

AI.FONSO REYES, letras de la Nueva España, 1948.

JOSE ROJAS GARCIDUEÑAS, Bernardo de Balbuena. La vida y la obra, 1958.

JOHN VAN HORNE, II "Bernardo" of Bernardo de Babuena. A Situdy of the Pown with Particular Atlention to its Relations to the Epics of Boiardo and Ariosto and to its Significance in the Spanish Renaissance, 1927.

JOHN VAN HORNE, Bermardo de Balbuena, 1940.

JOHN VAN HORNE, la grandeza mevicana de Bernarde de Balbuena, 1940. 